\title{
HỆ THỐNG GIÁO TRİNH VÀ TÀI LIỆU THAM KHẢO- ĐIỀU KIỆN CẦN THIẾT ĐỂ ĐÀO TẠO TÍN CHỈ
}

\author{
ThS. Nguyễn Lê Vinh - Giảng viên Khoa Du lịch \\ PGS.TS. Hà Nam Khánh Giao - Trưởng Khoa Du Lịch
}

\section{TÓM TÁT}

Chất luợng đào tạo của một truòng đại học phụ thuộc nhiều vào chất luợng và số lượng của hệ thống giáo trình và tài liệu tham khảo. Nghiên cưu này đi sâu vào phân tích nhằm làm rõ vai trò quan trọng của hệ thống giáo trình và tài liệu tham khảo trong trường đại học triển khai đào tạo tín chí.

Tù khóa: giáo trình, tài liệu tham khảo, đào tạo tín chỉ

\section{SYSTEMS OF TEXTBOOKS AND REFERENCES - NEEDED CONDITION FOR CREDIT-BASED TRAINING}

\begin{abstract}
The quality of a University training service is dependent dramatically on the numbers and the quality of the systems of textbooks and references. This research aims at analyzing the important role of the systems of textbooks and references in the credit-based training University.
\end{abstract}

Keywords: textbooks, references, credit-based training

Để bắt đầu bài viết, chúng tôi xin bàn đến việc những thành quả nghiên cứu quan trọng được đúc kết trong các viện nghiên cứu, các trường đại học là những tài sản vô giá và đôi khi là bí mật của các quốc gia nói chung. Những kết quả nghiên cứu khoa học được đúc kết thành lý thuyết và trình bày dưới dạng sách hoặc bài viết chuyên khảo, và đến giai đoạn nào đó sẽ được đưa vào giảng dạy để chuyển giao kiến thức cho thế hệ kế tiếp. Ví dụ, các lý thuyết về trò chơi và hành vi trong kinh tế của John V. Neumann, lý thuyết về trạng thái cân bằng trò chơi Nash (Nash Equilibrium) và một số lý thuyết khác được đúc kết thành các sách Lý thuyết Trò chơi (Game Theory) để giảng dạy. Muốn trở thành kinh tế gia hoặc chiến lược gia xuất sắc, rõ ràng không thể không học qua những "giáo trình" hay "bí kíp" này được. 
Một trường đại học không thể thiếu các giáo trình, tài liệu học tập. Chất lượng đào tạo của trường phụ thuộc một phần không nhỏ vào chất lượng giáo trình. Thậm chí, hiện đã có các trường áp dụng phương thức chuyển giao kiến thức chủ yếu qua tài liệu - ví dụ lối học hàm thụ ngày xưa hoặc các khóa đào tạo từ xa hiện nay. Để đi sâu vào phân tích nhằm làm rõ vai trò quan trọng của hệ thống giáo trình tài liệu trong trường đại học, trước hết chúng ta cần làm rõ một số khái niệm sau.

Giáo trình (Textbook) là sách hoặc các tài liệu viết khác được sử dụng chính trong môn học. Bên cạnh đó, còn có những "tài liệu" khác không thuộc dạng sách nhưng vẫn được sử dụng làm tài liệu học chính, phim ảnh, video clip, các tài liệu nghe nhìn khác chẳng hạn. Thông thường, các bộ môn trong trường Đại học phải có quyết định rõ ràng về việc chọn lựa giáo trình cho các môn học mà bộ môn phụ trách. Các quyết định này phải được lãnh đạo cao hơn phê chuẩn và được công bố rộng rãi cho sinh viên biết. Để thuận lợi cho việc giảng dạy và học tập, rất nhiều giáo trình mới trên thế giới hiện đã tích hợp cả công nghệ giảng dạy kèm theo như tài liệu tham khảo, bài tập, bài giảng chuẩn bị sẵn cho giảng viên (powerpoint slides), ngân hàng đề thi và đáp án.. v..v.

Với tầm quan trọng như vậy, có thể nói giáo trình môn học là xương sống của môn học mà các hoạt động dạy và học, các chủ thể thực hiện hoạt động đó (giảng viên, sinh viên, các đơn vị trong nhà trường) dựa vào để thực thi nhiệm vụ của mình. Hầu hết các khâu của quá trình đào tạo, từ dạy và học, kiểm tra đánh giá môn học, mua sắm trang thiết bị phục vụ môn học cho tới khâu tuyển dụng giảng viên đều phải căn cứ vào giáo trình môn học. Chẳng hạn, nếu bộ môn quyết định sử dụng một giáo trình tiếng Anh nào đó cho môn học thì việc tuyển dụng giảng viên có thể chuyển ngữ tiếng Anh sang tiếng Việt cho sinh viên là cần thiết.

Việc chuẩn hóa ngay từ đầu trong việc lựa chọn giáo trình giúp cho công tác kết nối các khâu của quá trình đào tạo dễ dàng hơn. Việc dạy và đánh giá học phần cho sinh viên cũng sẽ tránh được tình huống "dạy một đằng, thi một nẻo" thường xảy ra khi có sự thay đổi giảng viên giảng dạy, khi sinh viên thi lại hoặc học lại với các khóa sau. Khi triển khai đào tạo theo học chế tín chỉ, giáo trình môn học thể hiện khối lượng kiến thức được quy định tương ứng với số tín chỉ của môn học. Như vậy, bộ môn không thể sử dụng một giáo trình quá dài (nhiều tín chỉ, dành cho chuyên ngành) để giảng dạy cho môn học đó nhưng ở vị trí là môn học tự chọn (có số tín chỉ ít hơn) ở chuyên ngành khác. Trong trường hợp này, bộ môn phải bớt một số chương trong giáo trình đó hoặc chọn một giáo trình khác ngắn hơn. Như vậy, chỉ có một số ít giáo trình đáp ứng được điều kiện có thể giảmbớt số chương nhưng phần còn lại vẫn đảm bảo khối lượng kiến thức cốt lõi.

Bên cạnh đó, đào tạo theo học chế tín chỉ đòi hỏi phải phân định rõ khối lượng kiến thức cần được giảng dạy trên lớp và khối lượng kiến thức tự học. Giảng viên phải nêu rõ phạm vi kiến thức tự học cho sinh viên cũng như đảm bảo có giáo trình thích hợp để 
sinh viên tự học. Trong quá trình đào tạo theo niên chế trước đây, giáo trình gần như được khoán gọn cho giảng viên tự chọn sử dụng, nhất là giảng viên thỉnh giảng. Do vậy, những sinh viên phải học lại, thi lại sẽ gặp rất nhiều khó khăn khi có sự thay đổi về giảng viên kéo theo sự thay đổi về giáo trình và nội dung đề thi. Nhà trường cũng khó tổ chức thi lại chung cho các lớp, các khóa vì sự khác biệt trong giảng dạy trong cùng một môn học, và điều này làm tăng chi phí đào tạo nói chung cũng như khả năng phát sinh nhiều vướng mắc.

Việc chọn lớp trong đào tạo tín chỉ cũng có liên quan đến giáo trình. Theo đó, nếu giáo trình không được chuẩn hóa thì sinh viên sẽ có xu hướng chọn lớp (hoặc thầy) sử dụng giáo trình ngắn và dễ hơn, nếu được. Điều này làm cho công tác đánh giá giảng viên trở nên phức tạp hơn, việc đánh giá và so sánh kết quả học tập của sinh viên cũng trở nên khó khăn, có thể bị lệch lạc, khó điều chỉnh. Kết quả cuối cùng là nhà quản lý không thể biết rõ rằng liệu kết quả học tập của sinh viên có phản ảnh được chất lượng đào tạo hay không.

Với tính chất chuẩn hóa và ổn định như vậy, giáo trình môn học ít nhiều sẽ lạc hậu. Để cập nhật những kiến thức, thông tin mới của môn học mà giáo trình còn thiếu, giảng viên sẽ chủ động bổ sung thêm các tài liệu tham khảo. Nguồn tài liệu tham khảo vô cùng phong phú, từ sách chuyên khảo, bài báo cho đến phim ảnh, tạp chí thông thường. Ngoài ra, tài liệu tham khảo có thể được dùng để minh họa cho các lý thuyết trong giáo trình, hoặc được sử dụng để làm các nghiên cứu tình huống phục vụ cho môn học. Như vậy, giáo trình và tài liệu tham khảo là hai thành phần có liên quan chặt chẽ với nhau trong một hệ thống, hệ thống đó là kiến thức môn học cần được chuyển giao. Vậy giáo trình tài liệu ở vào vị trí như thế nào trong chương trình đào tạo (curriculum)?

Chương trình đào tạo là toàn bộ nội dung đào tạo và nhũng điều kiện để chuyển giao nội dung đào tạo đó. Nội dung đào tạo bao gồm khung chương trình đào tạo và các đề cương chi tiết các môn học tương ứng cùng với hệ thống giáo trình và tài liệu tham khảo. Nội dung đào tạo trả lời câu hỏi "dạy cái gì" và là yếu tố tạm gọi là $p h a \hat{a} n$ mềm của chương trình đào tạo, tức là toàn bộ khối lượng kiến thức cần chuyển giao.

Điều kiện để chuyển giao nội dung đào tạo bao gồm giảng viên, thư viện với đầy đủ hệ thống giáo trình tài liệu tham khảo các môn học và cơ sở vật chất, các phương tiện và dịch vụ phục vụ giảng viên, sinh viên và một số điều kiện khác về người học, người sử dụng lao động và môi trường bên ngoài. Đây là yếu tố tạm gọi là phần cúng của chương trình đào tạo và là câu trả lời cho câu hỏi: "dạy như thế nào".

Như vậy, giáo trình và tài liệu tham khảo ở vào vị thế trung tâm và ổn định của chương trình đào tạo. Chúng ta có thể thay đổi các điều kiện giảng dạy nhằm đáp ứng sự thay đổi nội dung chương trình đào tạo nhưng không thể làm đảo ngược quy trình. Vì vậy, 
để giữ cho hệ thống đào tạo theo tín chỉ ổn định, chúng ta cần phải chuẩn hóa các giáo trình và tài liệu tham khảo.

Nếu xét đến đòi hỏi đổi mới chương trình đào tạo, điều quan trọng nhất là đổi mới nội dung đào tạo. Tuy nhiên, để việc đổi mới nội dung đào tạo diễn ra thuận lợi và nhanh chóng, các điều kiện để chuyển giao nội dung đào tạo cũng phải được chú ý để thay đổi tương ứng. Trong hoàn cảnh của Việt Nam hiện nay, có thể nói trong thời gian qua các trường khối khoa học xã hội và nhân văn, đặc biệt là khối ngành kinh tế - quản trị kinh doanh - đã trải qua một đợt đổi mới nội dung đào tạo hết sức mạnh mẽ, thành công ngoạn mục với một nguồn lực ít ỏi; tuy với giá phải trả cũng không nhỏ.

Chính vì vậy, theo chúng tôi việc đầu tư vào đổi mới nội dung đào tạo mà trọng tâm là đổi mới và hoàn chỉnh hệ thống giáo trình tài liệu tham khảo là một sự đầu tư khôn ngoan, đi tắt đón đầu nhằm nâng cao chất lượng đào tạo. Suy cho cùng, việc mua (hay photocopy!) giáo trình, tài liệu tham khảo là ít tốn kém nhất trong danh mục đầu tư cho một trường đại học. Một bí mật quốc gia trị giá hàng tỷ đô la có khi được viết trên những tờ giấy hoặc dưới dạng file tin học đơn giản mà thôi.

Lâu nay, nói đến chất lượng giáo dục đại học, thông thường người ta hay nghĩ đến chất lượng người thầy, đó là điều hoàn toàn đúng đắn. Nhưng bên cạnh đó, thiết nghĩ chúng ta cũng cần quan tâm hơn nữa đến hệ thống giáo trình tài liệu tham khảo như là yếu tố trọng tâm của chất lượng. Để việc triển khai đào tạo theo học chế tín chỉ, điều có thể làm ngay và tương đối dễ triển khai là ban hành danh mục môn học kèm theo giáo trình, tài liệu tham khảo đã được chắt lọc để đảm bảo tính xuất sắc và tiên tiến nhất. Bước tiếp theo là hoàn thiện tất cả đề cương chi tiết các môn học (đòi hỏi nhiều thời gian hơn, và cũng linh hoạt hơn, phụ thuộc vào giáo trình môn học được chọn). Đây cũng là yêu cầu bắt buộc và là nội dung quan trọng trong kiểm định chất lượng trường đại học.

\section{TÀI LIỆU THAM KHẢO}

Bartels, F. L., Giao, H. N. K., \& Ohlenburg, T. J. (2006). ASEAN Multinational Entreprises: A Structural Analysis of Strategic Coherence. ASEAN Economic Bulletin, 23(2), 171-191. doi:10.1355/AE23-2C

Giao, H. N. K. (1996a). Hướng dẫn tóm tắt Chiến lược Công ty. Thành phố Hồ Chí Minh: Nhà Xuất bản Thống kê.

Giao, H. N. K. (1996b). Quản trị Tiếp thị Toàn cầu. Thành phố Hồ Chí Minh: Nhà Xuất bản Thống kê.

Giao, H. N. K. (2004a). Diễn thuyết trước Công chúng-Làm sao để thu hút Khán giả? Thành phố Hồ Chí Minh: Nhà Xuất bản Thống kê. 
Giao, H. N. K. (2004b). Kỹ năng làm việc-Skills for Success (S4S) (Vol. 2): Nhà Xuất bản Thống kê.

Giao, H. N. K. (2004c). Kũ năng làm việc - Skills for Success (S4S) (Vol. 1). Thành phố Hồ Chí Minh: Nhà Xuất bản Thống kê.

Giao, H. N. K. (2004d). Kỹ năng Thương lương- 7 bước RESPECT. Thành phố Hồ Chí Minh: Nhà Xuất bản Thống kê.

Giao, H. N. K. (2004e). Marketing Công nghiệp- Phục vu Khách hàng là các Tổ chức. Thành phố Hồ Chí Minh: Nhà Xuất bản Thống kê.

Giao, H. N. K. (2004f). Marketing Dịch vu- Mô hình 5 Khoảng cách Chất luợng Dịch $v u$. Thành phố Hồ Chí Minh: Nhà Xuất bản Thống kê.

Giao, H. N. K. (2004g). Marketing Dịch vu- Phục vu Khách hàng tốt hơn. Thành phố Hồ Chí Minh: Nhà Xuất bản Thống kê.

Giao, H. N. K. (2004h). Quan hệ Công chúng- Để người khác gọi ta là PR. Thành phố Hồ Chí Minh: Nhà Xuất bản Thống kê.

Giao, H. N. K. (2004i). Quản trị Bán hàng- Đội ngũ Bán hàng tốt chura? . Thành phố Hồ Chí Minh: Nhà Xuất bản Thống kê.

Giao, H. N. K. (2004j). Quản trị Chiến lược Công ty-Phát huy Tiềm lực Cạnh tranh (Vol. 2). Thành phố Hồ Chí Minh: Nhà Xuất bản Thống kê.

Giao, H. N. K. (2004k). Quản trị Chiến lược Công ty-Phát huy Tiềm lực Cạnh tranh (Vol. 1). Thành phố Hồ Chí Minh: Nhà Xuất bản Thống kê.

Giao, H. N. K. (20041). Quản trị Công ty Đa quốc gia- Quản lý tù sự đa dạng Văn hóa (Vol. 2). Thành phố Hồ Chí Minh: Nhà Xuất bản Thống kê.

Giao, H. N. K. (2004m). Quản trị Công ty Đa quốc gia- Quản lý tù sụ đa dạng Văn hóa (Vol. 1). Thành phố Hồ Chí Minh: Nhà Xuất bản Thống kê.

Giao, H. N. K. (2004n). Quản trị học- Để Quản lý không còn là quá khó (Vol. 2). Thành phố Hồ Chí Minh: Nhà Xuất bản Thống kê.

Giao, H. N. K. (2004o). Quản trị học- Để Quản lý không còn là quá khó (Vol. 1). Thành phố Hồ Chí Minh: Nhà Xuất bản Thống kê.

Giao, H. N. K. (2004p). Quản trị Marketing-Marketing để Chiến thắng. Thành phố Hồ Chí Minh: Nhà Xuất bản Thống kê. 
Giao, H. N. K. (2010). Mạn đàm thước đo Văn hóa Doanh nghiệp trong các Ngân hàng thương mại. Tạp chí Ngân hàng, Ngân hàng Nhà nước VN, 22, 25-27. doi:10.31219/osf.io/rtqz4

Giao, H. N. K. (2011). Giáo trình Marketing Du lịch. Thành phố Hồ Chí Minh: Nhà xuất bản Tổng hợp

Giao, H. N. K. (2012a). Giáo trình Cao học Quản trị Kinh doanh Quốc tế. Thành phố Hồ Chí Minh: Nhà xuất bản Tổng hợp.

Giao, H. N. K. (2012b, 16/06/2012). Học chiến luợc tù̀ doanh nghiệp siêu nhỏ- Tại sao không? Paper presented at the Hỗ trợ Doanh nghiệp nhỏ và vừa vượt qua khủng hoảng, Trường Đại học Tôn Đức Thắng.

Giao, H. N. K. (2012c). Về việc xếp hạng các truờng đại học Việt Nam. Tạp chí Nghiên cứu Tài chính- Marketing, 7-8, 77-80. doi:10.31219/osf.io/6yqem

Giao, H. N. K., \& Bình, N. V. (2011). Giáo trình Nghiệp vu Nhà hàng. Thành phố Hồ Chí Minh: Nhà xuất bản Tổng hợp.

Giao, H. N. K., \& Bình, N. V. (2014). Giáo trình Nghiệp vu Nhà hàng. Hà Nội: Nhà Xuất bản Thống kê.

Giao, H. N. K., Bình, N. V., \& Tùng, N. S. (2014). Giáo trình Quản trị Kinh doanh Khách sạn. Hà Nội: Nhà Xuất bản Thống kê.

Giao, H. N. K., Hoan, N. C., Dũng, T. Q., Vinh, N. L., \& Anh, L. T. L. (2014). Giáo trình Quản trị Kinh doanh Lũ hành. Hà Nội: Nhà Xuất bản Thống kê.

Giao, H. N. K., Ly, P. T. T., \& Giang, N. T. Q. (2010). Giáo trình Giao Tiếp Kinh Doanh. Thành phố Hồ Chí Minh: Nhà Xuất bản Lao động - Xã hội.

Giao, H. N. K., \& Sơn, L. T. (2014). Giáo trình Quản trị Chiến lược cho tổ chức Du lịch. Hà Nội: Nhà Xuất bản Thống kê. 